\title{
ANALYSIS OF PUMP-PIPE LINE SYSTEM USING ELASTIC THEORY OF FLUID TRANSIENTS
}

\author{
N. Ruben ${ }^{1}$, E.Venkata Rathnam ${ }^{2}$ \\ ${ }^{1}$ Research Scholar, Department of Civil Engineering, NIT, Warangal, Email: rubennerella2512@gmail.com \\ ${ }^{2}$ Associate Professor, Department of Civil Engineering, NIT, Warangal, Email: evr@nitw.ac.in
}

\begin{abstract}
The conditions like pump trip or power failure to pumps can create the extreme pressure fluctuations in pump-pipeline systems which may be the case of increase in maximum pressure head or decrease in minimum pressure head and even reaching to subatmospheric pressure conditions.Simulation of these extreme events could help the designer to take necessary precautions like increasing the thickness of the pipeline orproviding suitablesurge protection devices for the entire pump-pipeline system. Due to complexity nature of hyperbolic partial differential equations involved to describe these extreme events, various numerical methods were available.One such numerical method is called the method of characteristics (MOC) and is widely used to compute the fluid transients which may occur in pump-pipeline system. The objective of the study in the present paper is to analyze hydraulic transient pressuresfor the case of power trip to pumps byusing Elastic theory based on MOCapproach. A case study of J.C.R.Devadula Lift scheme in Telangana State, India is presented. It is observed that water column separation has occurred on downstream of pump delivery and hence transient control device like air vessels and one-way surge tanks are to be planned for this pipeline system.
\end{abstract}

Key words: Fluid transients, pump trip, elastic theory, method of characteristics.

\section{INTRODUCTION}

In pumping mains, changes in flow may be caused by (a) starting or stopping of pumps, (b) opening or closing of valvesand (c) Power failure (Pump trip). The first two conditions ( $a, b)$ may consider as planned conditions whereas thethird condition (c) may be unexpected and which form the most critical transient (water hammer) condition in pumping mains. Prediction and verification of maximum and minimum transient pressures are important to design the pipeline system due to these extreme conditions.Pipe bursts, pipe rupture could be avoided by increasing pipe wall thickness and water column separation, pipe collapse could be avoided by installing suitable water hammer protection devices at appropriate locations along the system[1]. A few protection devices could be air chamber, zero velocity valves, pressure relief valves, stand pipe and surge tanks etc.

\section{LITERATURE REVIEW}

The pipe system may undergo extreme pressures in a variety of conditions. One of such condition is pump trip or power failure to pumps. When pumptrip occurs, the initial pump head decreases as pump speed decreases. This pressure drops travels with acoustic speed towards the delivery end. During the initialpressure drop and also at high altitudes (locations) in the pipeline profile the pressure condition may reaches to vapour pressure of the fluid. This is called water column separation. Due to dynamics of flow in the system, at some instant, the cavity collapse creating a shock pressure rise and may cause pressure to exceed the test pressure of the pipe[2]. These negative pressuresmaydamage the pipe systemwhichincludesstructural buckling or collapse and failing of pipe joints[3], contamination of potable water[4], and vaporous cavitation or liquid column separation which could result in column separation with large water hammer pressures[5].Numerous works have been reported on pump-pipe lines that were subjected to transients. Notable works are from [6], [7],[8], [9],[10].

\section{METHODOLOGY AND RESULTS}

One simple numerical solution technique for solving the water hammer equations Eq. (1) and Eq. (2) is called as method of characteristics (MOC). This is one dimensional steady state friction model. Description on MOCcan be found in standard text books viz.,[2][3].

$$
\begin{gathered}
\frac{\partial H}{\partial t}+\frac{a^{2}}{g A} \frac{\partial Q}{\partial x}=0 \\
\frac{\partial Q}{\partial t}+g A \frac{\partial H}{\partial x}+f \frac{Q|Q|}{2 D A}=0
\end{gathered}
$$

where $\mathrm{H}=$ piezometric head, $\mathrm{t}=$ time, $\mathrm{a}=$ wave speed and $\mathrm{g}=$ gravitational acceleration; $\mathrm{A}=\mathrm{c} / \mathrm{s}$ sectional area of pipe, $\mathrm{Q}=$ flow rate, $\mathrm{x}=$ distance, $\mathrm{f}=$ friction factor and $\mathrm{D}=$ pipe inner diameter respectively.

In the present work the first reach pipe line of J.C.R. Devadula lift scheme is considered.The pump and pipeline data as follows: Number of pumps(parallel $)=2$;rated 
discharge $Q_{R}=14 \mathrm{~m}^{3} / \mathrm{s}$; rated pump head $\mathrm{H}_{\mathrm{R}}=131 \mathrm{~m}$; rated speed $\mathrm{N}_{\mathrm{R}}=500 \mathrm{rpm}$; rated power $\mathrm{P}_{\mathrm{R}}=9900 \mathrm{kw}$; pump efficiency $=91 \%$; pump-motor inertia $=14000 \mathrm{~kg}-\mathrm{m}^{2} ;$ specific speed $=0.65$; total length of pipeline $=38352 \mathrm{~m}$;pipe material $=$ mild steel;pipe diameter $=3 \mathrm{~m}$;pipe thickness $=16 \mathrm{~mm}$; steady state flow velocity $=1.98 \mathrm{~m} / \mathrm{s}$; pressure wave speed $=870 \mathrm{~m} / \mathrm{s}$. The steady state hydraulic gradient line of the pump-pipe system is shown in Fig.1. The simulated pressure heads after power trip to pumps is shown in Fig.2.Maximum and Minimum Hydraulic Grade Line after pump trip are shown in Fig.3.

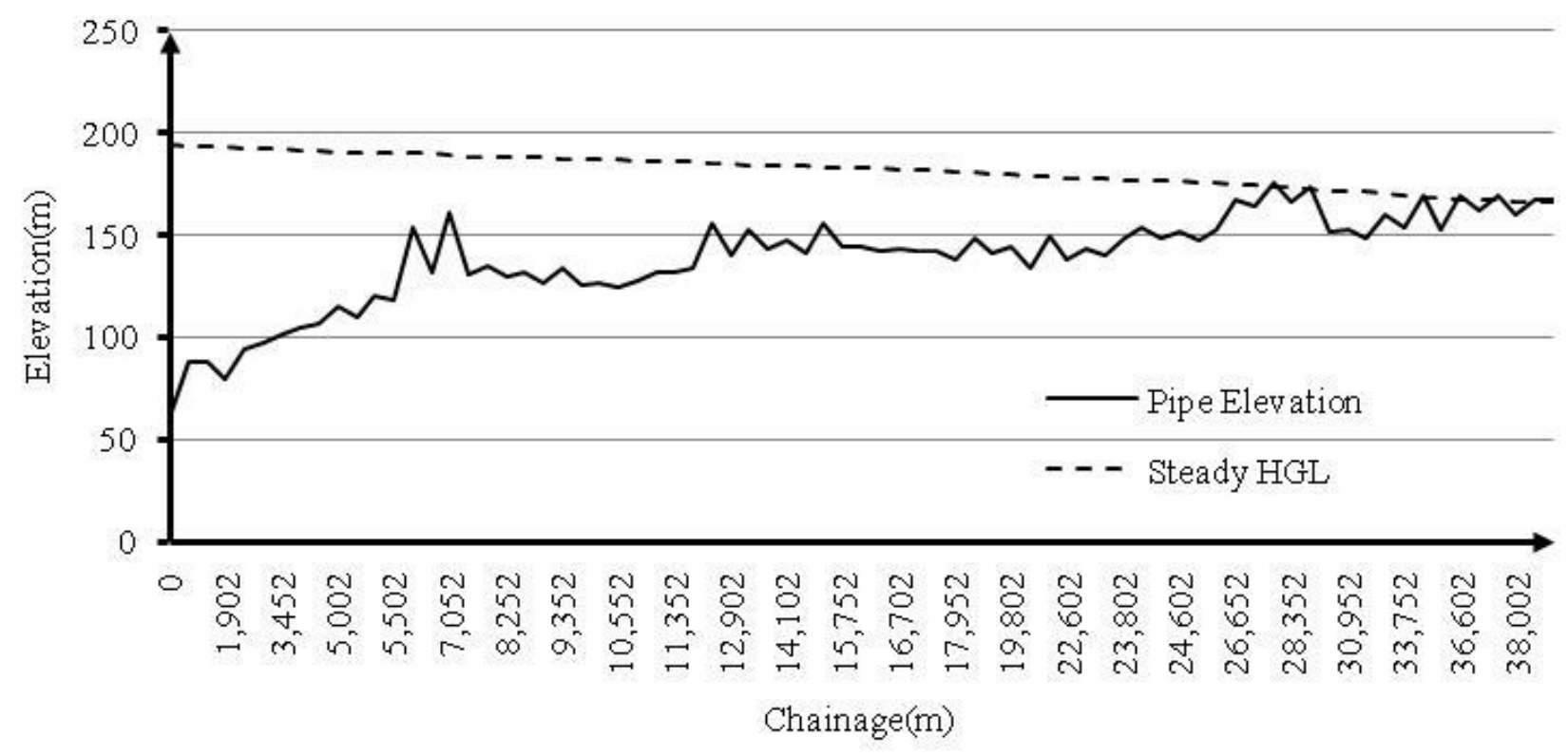

Fig-1: Steady state HGL

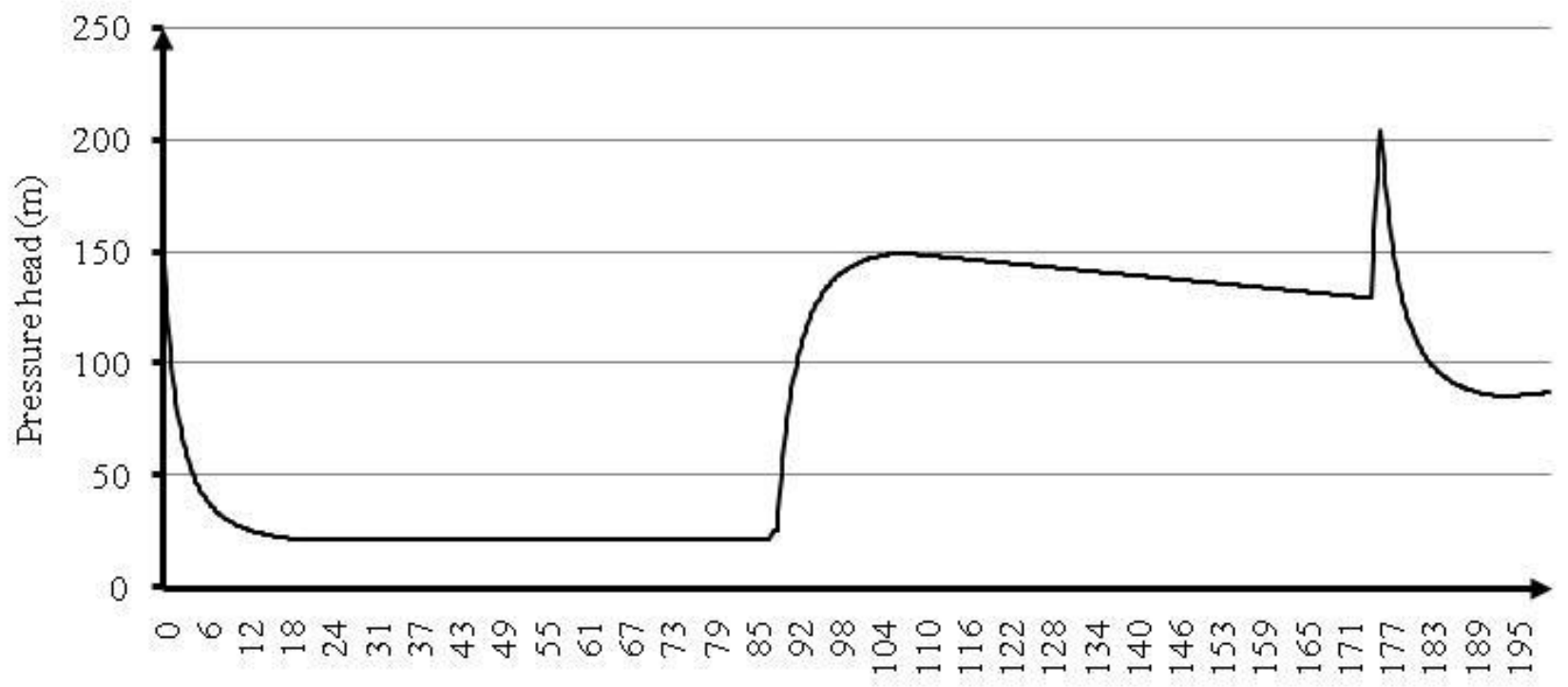

Time(s)

Fig- 2: Pressure head variation near the pump after pump trip 


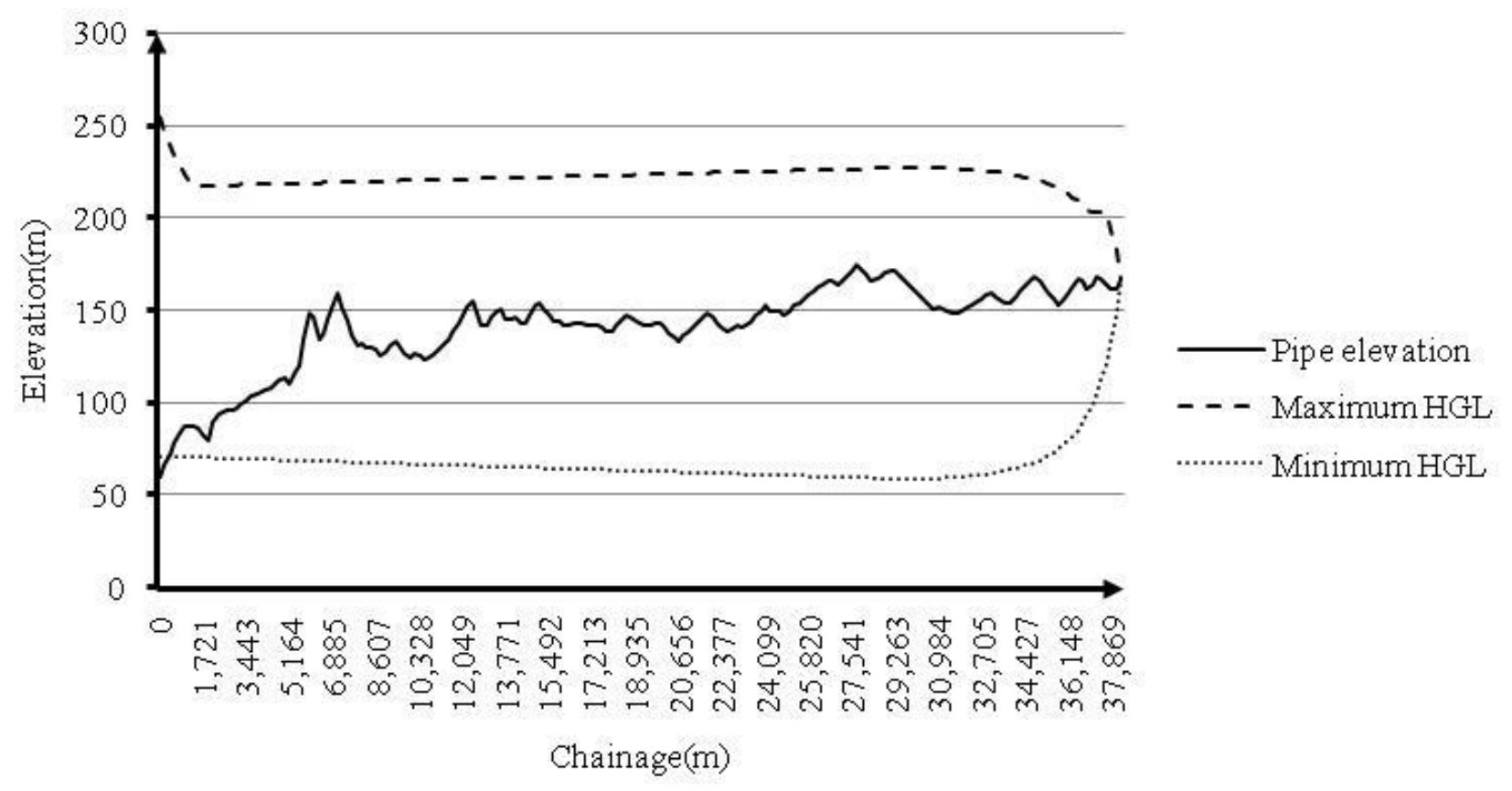

Fig- 3: Maximum and minimum hydraulic grade line (HGL) after pump trip

\section{SUMMARY AND CONCLUSIONS}

- $\quad$ Elastic theory based MOC model is applied to J.C.R. Devadula Lift Schemepumping main to determine the extreme pressure heads after power trip to pumps.

- The extreme pressure heads (both maximum and minimum) are observed immediately after power failure to pumps. It was noticed that water column separation phenomenahas occurred within 6 seconds after power failure to pumps, very near to pump location.Planning of air vessel is necessary on the downstream of pumps to control negative surges in the pressure main.

- As the profile of the pipeline system ison undulating terrain, planning of one-way surge tank is necessary at $28.5 \mathrm{~km}$ chainage, to absorb the upsurges and release water to pressure main during down surge development.

\section{REFERENCES}

[1] A. K. Soares, I. C. Covas, and H. M. Ramos, "Damping analysis of hydraulic transients in pumprising main systems," J .Hydraul .Eng., vol. 139, no. 2, pp. 233-243, 2013.

[2] E. B. Wylie and V. L. Streeter, Fluid Transients. McGraw-Hill, U.S.A, 1978.

[3] M. H. Chaudary, "Applied Hydraulic Transients," Van Nostrand Reinhold ,Newyork, 1987.

[4] M. S. Ghidaoui, M. Zhao, D. A. McInnis, and D. H. Axworthy, "A review of water hammer- Theory and Practice," Appl. Mech. Rev., vol. 58, no. 1, pp. 4976, 2005.

[5] A. Malekpour and B. W. Karney, "Profile-induced column separation and rejoining during rapid pipeline filling," J.Hydraul. Eng., pp. 1-12, 2014.
[6] D. H. Axworthy and B. W. Karney, "Transient analysis with time-decoupled pumping station," $J$ .Hydraul. Eng., vol. 124, no. 3, pp. 301-306, 1998.

[7] J. Izquierdo and P. L. Iglesias, "Mathematical Modelling of Hydraulic Transients in Simple Systems," mathmatical Comput. Model., vol. 35, pp. 801-812, 2002.

[8] D. J. Wood, "Waterhammer analysis-Essential and Easy (and Efficient)," J. Environ.Eng., vol. 131, no. August, pp. 1123-1131, 2005.

[9] A. Adamkowski and M. Lewandowski, "Investigation of hydraulic transients in a pipeline with column separation," j.Hydraul. Eng., vol. 138, no. 11, pp. 935-944, 2012.

[10] A. Bergant, A. R. Simpson, and Tijeeeling A.S., "Water hammer with column separation: A historical review," J. Fluids Struct., vol. 22, pp. 135-171, 2006. 